\title{
Study on EFL English Reading Strategies and Metacognitive Awareness Based on Sound Thinking Method
}

\author{
HuSisi \\ Nanchang Institute of Science \&Technology, Nanchang 330108, China
}

\begin{abstract}
Keywords: Metacognitive awareness, Sound thinking, Reading strategy, EFL reading, Quantitative analysis.
\end{abstract}

\begin{abstract}
In order to study the relationship between English reading strategies and metacognitive awareness, this paper proposes a sound thinking method and uses the quantitative and qualitative analysis to carry on the thorough discussion. Through the analysis, it is found that there is a correlation between English reading strategies and reading proficiency. Compared with lower reading level students, the students with higher reading level are more inclined to use the global strategy to solve the reading problem, but there is no obvious difference between the two kinds of students for the number of using strategies. The students with higher reading level have different quality of reading strategies than the students with lower reading level, and the students with higher reading skills are more inclined to use the metacognitive awareness, which is more flexible and can get better results. Through the analysis of the differences in reading strategies, this paper provides a valuable reference for the teaching of EFL reading.
\end{abstract}

\section{Introduction}

Metacognition is cognitive subject on the cognitive of self -cognitive activities. In EFL reading, metacognition is a cognitive process of reading comprehension [1-3]. The use of reading strategies can make up for the lack of English language proficiency, which can effectively improve the reading memory, so as to improve the efficiency of reading. The effective use of reading strategies depends on the metacognitive awareness, and different reading levels have different metacognitive awareness and flexibility on the reading target and solving the reading problem [4,5]. Through the metacognitive awareness, it can help reader adjust the reading strategies and monitor the reading process, and at the same time it can improve the reading strategies under the guidance of the teacher, so as to improve the reading ability.

\section{EFL English Reading Strategy Metacognitive Awareness}

Domestic and foreign scholars discussed the relationship between metacognitive awareness and reading strategy, when they studied ESL/EFL reading metacognition. Research shows that the reading strategy can be divided into two types, one is the global strategy, and another is the local strategy [6-8]. The overall strategy is read through the process of top-down information processing, so people will use the reading strategies; local strategy is generally a bottom-up decoding strategy, the use of this strategy is also related to the level of reading. The general higher reading level students is positively related to the overall strategy and reading achievement, and the students with lower reading level have positive correlation with the use of local strategy and reading achievement [9-11]. In order to improve the use of reading strategies, the students can improve their reading level by the effective use of metacognitive awareness, and the process is shown in Figure 1. 


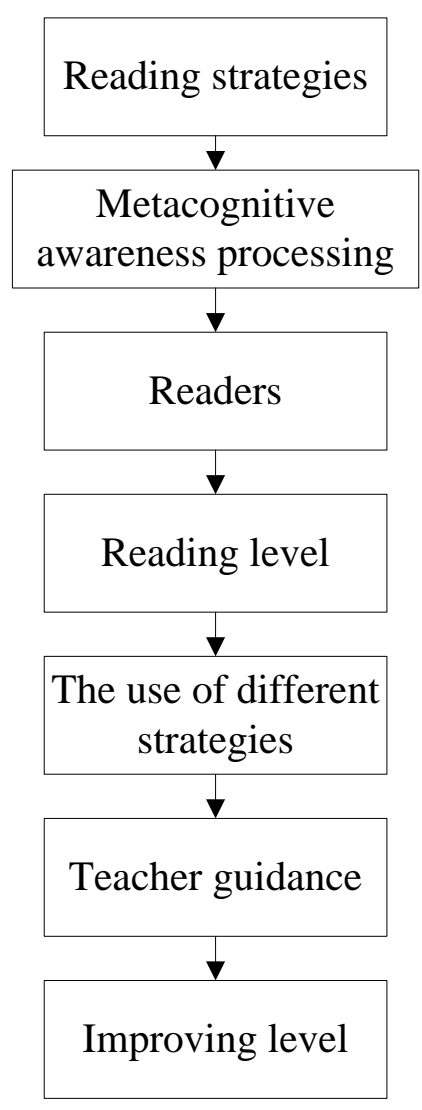

Fig. 1 The flow chart of improving reading level

Figure 1 shows the flow chart of improving the reading level. According to different reading level, reading can choose different reading strategies choose different reading strategies, and under the guidance of teachers, people can strengthen the metacognitive awareness of reading strategies, so as to improve the reading level. For the Chinese EFL learners, reading is a very important learning method, which has a direct impact on the learning effect. In previous studies, the researchers chose non English majors as the subjects, it is difficult to investigate the use of metacognitive awareness of reading strategies, and however this study uses sound thinking method to explore the relationship between reading strategies and metacognitive awareness of English majors, this method presents new findings in this field and provides guidance for English teaching practice.

\section{Experimental Teaching Steps}

In the experimental teaching, this paper selects 6 students to carry out the pilot experiment. In the process of experiment, it is found that there are three aspects of the problem, the first is to be tested easily to produce a nervous tension, so that the effect of sound thinking is not satisfactory; the second is that the subjects do not have warm-up training, direct participation in the experiment will produce a sense of non-adaptation, and finally the difficulty of reading materials will have a direct impact on the level of sound thinking; if people do not deal with these three problems, the experiment cannot achieve the desired purpose.

In view of the above three problems, the subjects should carry out half an hour of sound thinking and psychological counseling before the test. The subjects are told the detailed experimental purposes and methods to carry out demonstration for the sound thinking method [12,13]. In the experiment, people should explain the use of the strategy, such as in the non-understanding place to read a word, people can read with questions after reading problem. After a full understanding of the testing experiment, the subjects can carry out the warm-up training. After mastering the method of reading and sound thinking, the subjects begin the official text reading and record the reading report.

In the process of sound thinking test, the subjects is to answer the question of reading comprehension, they need to use English or Chinese to speak the thinking and ideas in the head. In the 
process of the experiment, the high precision recording equipment is used to make a detailed record for the subjects' answer and report, and finally the average recording is 18 minutes 58 seconds through the sound thinking test [14]. In the end of sound thinking, the researchers carry out the subjects return visit through the tape recorder. According to the reading strategies used by the subjects, this paper carries out inquiry and confirmation to further understand the understanding degree of the subjects' reading materials.

\section{Teaching Experiment Data Analysis}

According to the effective index of the teaching experiment test, silent time report exceeds total reporting time $20 \%$, it will be classified as invalid report, and so 8 unqualified reports are removed in this test [15]. After the rest of the report analysis, the reading strategies are classified, and then the reading strategies are classified, finally we can obtain an overall strategy for 18, solving the problem strategy for 12 and supporting strategy for 8 . Through the analysis of reading strategies for students with higher reading level, this paper can obtain the strategies relationship as shown in Figure 2.

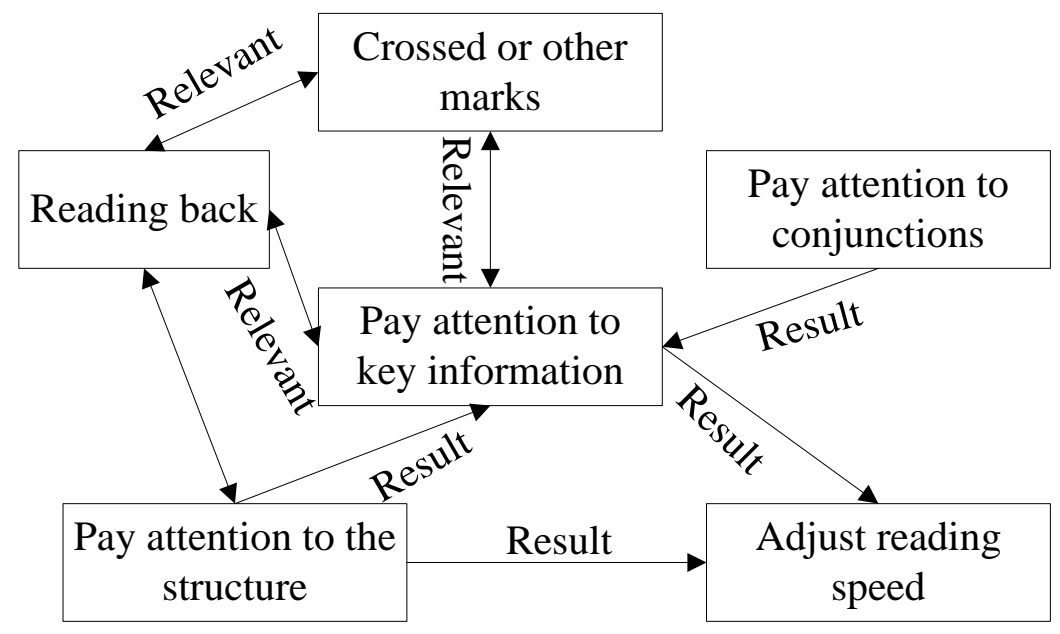

Fig.2 High level reading strategy diagram

Figure 2 shows the relationship diagram of high level reading strategies, the main performance of the reading strategies is related and result. There are a variety of reading strategies, which mainly include the article structure reading, connecting words reading and key information reading, and the key information reading is also related to the mark reading and back reading. A higher level of reading will produce a sound thinking when they do not know words in reading, to return to the previous search for specific explanation, such as against, expressing opposition. Readers with higher reading levels always use the most appropriate reading strategies; low levels of reading will also be used to mark and return to read, but they tend to look at the East sentence or the West look at a word, they cannot find the key information as a mark, they simply label a form, but not enough to understand the reading information, nor play information to enhance understanding and memory function. High level readers and low level readers use the same reading strategy on the surface, but the actual arrival cognitive goals and effects are different, this is due to the higher level reader than the low level reader are more inclined to use the global strategy to solve the reading problem, at the same time they can more flexible use reading strategies after the higher level readers use the metacognitive awareness, they can get better reading results. 
Table 1. The use of metacognitive awareness between the experimental class and the control class

\begin{tabular}{|c|c|c|c|c|c|c|}
\hline & \multicolumn{2}{|c|}{ Pre test } & \multicolumn{2}{|c|}{ Post test } & \multirow{2}{*}{$\begin{array}{c}t \text { value } \\
P \sim 0.01\end{array}$} \\
\hline & & Mean value & $\begin{array}{l}\text { Standard } \\
\text { deviation }\end{array}$ & Mean value & $\begin{array}{l}\text { Standard } \\
\text { deviation }\end{array}$ & \\
\hline \multirow{3}{*}{ Control class } & Planning & 3.02 & 0.282 & 3.12 & 0.332 & $\begin{array}{l}-1.772 \\
\end{array}$ \\
\hline & Monitoring & 3.13 & 0.273 & 3.08 & 0.251 & -2.486 \\
\hline & Assessment & 2.98 & 0.245 & 3.02 & 0.324 & -1.662 \\
\hline \multirow{3}{*}{$\begin{array}{l}\text { Experimental } \\
\text { class }\end{array}$} & Planning & 3.01 & 0.268 & 3.41 & 0.369 & -8.236 \\
\hline & Monitoring & 3.12 & 0.331 & 3.52 & 0.439 & -8.235 \\
\hline & Assessment & 2.86 & 0.272 & 3.43 & 0.371 & -10.237 \\
\hline
\end{tabular}

In order to improve the use of students' metacognitive awareness in reading comprehension, the use of training method train the use of metacognitive awareness in English teaching experiment class. The results were statistically trained by means of questionnaire survey, the table 1 can be seen that the difference between control table's early and late stage testing is little, the difference between the experimental class's early and late stage is big, and the results are summarized as shown in Table 2.

Table 2. The comparison before and after total score test

\begin{tabular}{|c|c|c|c|c|c|}
\hline \multirow{2}{*}{} & \multicolumn{2}{|c|}{ Control class } & \multicolumn{2}{c|}{ Experimental class } & $t$ value \\
\cline { 2 - 6 } & Mean value & Standard deviation & $P \sim 0.01$ & Standard deviation & $P \sim 0.01$ \\
\hline Pre test & 3.09 & 0.232 & 3.08 & 0.278 & 0.882 \\
\hline Post test & 3.14 & 0.275 & 3.52 & 0.365 & -8.235 \\
\hline
\end{tabular}

To further analysis of the results, this paper obtains the comparison results before and after total score test as shown in Table 2. It can be seen that the pre experimental class and the control class are basically the same for the use of metacognitive awareness, while the latter training experimental class is significantly higher than control class. In English reading, the use of metacognitive strategies can significantly improve their reading in the use of the strategy for students to guide and training, which can improve students' reading ability.

\section{Summary}

This research shows English major students make use of different strategies in the EFL reading to improve the reading effect, in which the use of metacognition has a certain role in monitoring and regulation on reading strategies. There are some differences among higher reading level students and lower reading level students in the use of metacognition, in which the former is much more than the latter in the use of metacognitive awareness, and can be flexible use of metacognitive awareness to achieve reading goals. Therefore, teachers can appropriate metacognitive awareness training according to the students' reading ability and situation, to improve the students' English reading level.

\section{References}

[1] Q. Guan. The evidence of cross language learning psychological assessment from English reading motivation t reading level. Foreign teaching theory and practice, 2013(1): 12-14.

[2] Z.J. Qin, J.Y. Li. Second language reading strategy research for 30 years: review and prospect. Foreign language teaching, 2013(4): 43-49.

[3] Q.L. Wu, J.C. Luo, H.M. Yang. Study on the metacognitive awareness of English major students in English reading strategies. Journal of East China University of Science and Technology, 2013(4): 105-116. 
[4] L.P. Pan. An empirical study on the effectiveness of the ESL reading metacognitive strategy. Journal of Hangzhou Normal University, 2012(2): 122-118.

[5] J.Y. Wang, B.S. Jiang. The overall trend and macro reading strategies. Journal of Xi'an College of Foreign Languages, 2014(4): 63-60.

[6] X.M. Zeng. To improve English majors reading ability in the extracurricular training reading metacognitive strategy. Journal of PLA University of foreign language, 2013(6): 60-66.

[7] L.J. Song. The psychological characteristics of middle school students in English teaching. Educational exploration, 2011 (3): 55-56.

[8] Y.M. Zhu. A new thinking on improving students' learning interest and motivation in English teaching. China's off campus education, 2013(4): 105-106.

[9] Y. Yang. The advantages and disadvantages of multimedia teaching in English teaching. Journal of Jilin radio and Television University, 2013(6): 146-147.

[10] Y.H. Zhang. A study on the dynamic evaluation model of web writing teaching in College English. Foreign language circles, 2013(4): 73-81.

[11] X.Q. Wang. Theory and practice of higher mathematics stratified teaching mode. Jilin education, 2013(11): 20- 21.

[12] F.Y. Li. The application and thinking of multimedia in English teaching. China's information technology education. 2013(8): 43-44.

[13] Y.Q. Peng, J.Q. Wu. Analysis of the possibility of mobile micro learning based on mobile phone terminal . China education information, 2013(19): 13-15.

[14] W. Zheng, Y.J. Qi. The construction and application of mobile learning system in distance education. China distance education, 2013(3): 82-83.

[15] X.C. Gao. Research on distance open education mobile learning mode based on fragmentation learning. Journal of Jiamusi Education Institute, 2014(11): 24-25. 